\title{
INVESTIGATION OF THE EFFECTS OF WATERLINE SWITCH CAPACITANCE ON THE ELECTRICAL PREPULSE OF THE Z- ACCELERATOR*
}

\author{
R.W. Shoup \\ Defense Threat Reduction Agency \\ 1680 Texas Street S. E. \\ Kirtland Air Force Base, NM 87117-5669, USA \\ R. B. Spielman, K. W. Struve, and W. A. Stygar \\ Sandia National Laboratories \\ P. O. Box 5800, Mail Stop 1194 \\ Albuquerque, NM 87185-1194, USA
}

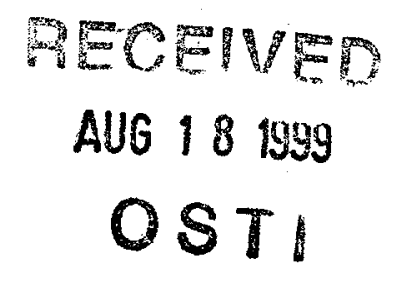

\section{Abstract}

The Z-accelerator at the Sandia National Laboratories (SNL) was modified in 1996 to deliver a 20 MA pulse to a $\mathrm{z}$-pinch load in $100 \mathrm{~ns}$. The pulsedpower driver is a 36-module waterline accelerator. Each waterline contains four self-break switches as part of the pulse-forming section. A study was conducted to investigate the effects of increasing the capacitance of the waterline switches on the shape of the electrical prepulse at the load. Past studies have shown that increasing the prepulse at the z-pinch load increases the $\mathrm{x}$-ray output power. In this study, one set of switches with its surrounding waterline hardware was modeled in 3-D and capacitance calculated using the electrostatic code, COULOMB. The capacitance values were used in a SCREAMER model of the Zaccelerator. SCREAMER, an SNL-developed, lumpedelement circuit code was used to calculate the timedependent current waveforms delivered to the z-pinch load. The design was changed and a new capacitance matrix and output waveforms were calculated. This paper presents the results of the COULOMB 3-D modeling, and the SCREAMER circuit-model analyses.

\section{INTRODUCTION}

In some applications of pulsed power accelerators it is desirable to produce an electrical output that contains no prepulse. A water switching technique was developed at Sandia National Laboratories which reduces the prepulse voltage by reducing the capacity across the waterline switch [1]. The switching technique allows the pulse forming lines to be stacked in parallel and electrically isolated from the load after the line has been discharged. On the Z-accelerator, the prepulse is suppressed by the use of a prepulse shield in the switch geometry.

In other applications, it is desirable to produce an output that contains a prepulse. In an experiment performed to investigate the influence of a prepulse current on a fiber z-pinch, it was reported [2] that the $x$-ray yield increased by several factors when the prepulse current increased.

In the subject study, the 3-D models of the waterline switch and associated hardware are developed for configurations with and without a prepulse shield. The computer code COULOMB [3] was used to develop the model and to calculate the capacitance of the switch for each case. The switch capacitance for each one was incorporated in the SCREAMER model of the Z-accelerator. SCREAMER [4] was used to calculate the resulting time-dependent current prepulse waveforms at the z-pinch load. The results of the COULOMB and SCREAMER analyses are presented for a waterline configured with and without a prepulse shield.

\section{THE SWITCH MODEL}

Each waterline in the pulse-forming section of the $Z$-accelerator contains four self-break switches, a prepulse shield, and supporting hardware. The geometrical model was developed in COULOMB using the computer-aided-drawing capabilities of the software. The waterline was modeled as a two-section metal cylinder. One section was drawn as a 68" diameter cylinder, 23" long. The second section was drawn as a 54" diameter cylinder, 22.5" long. The prepulse shield was modeled as a $0.5^{\prime \prime}$ thick plate, 54 "

\footnotetext{
* Work performed at Sandia National Laboratories. Sandia is a multi-program laboratory operated by Sandia Corporation, a Lockheed Martin Company for the United States Department of Energy under Contract No. DE-AC0494AL85000.
} 


\section{DISCLAIMER}

This report was prepared as an account of work sponsored by an agency of the United States Government. Neither the United States Government nor any agency thereof, nor any of their employees, make any warranty, express or implied, or assumes any legal liability or responsibility for the accuracy, completeness, or usefulness of any information, apparatus, product, or process disclosed, or represents that its use would not infringe privately owned rights. Reference herein to any specific commercial product, process, or service by trade name, trademark, manufacturer, or otherwise does not necessarily constitute or imply its endorsement, recommendation, or favoring by the United States Government or any agency thereof. The views and opinions of authors expressed herein do not necessarily state or reflect those of the United States Government or any agency thereof. 


\section{DISCLAIMER}

Portions of this document may be illegible in electronic image products. Images are produced from the best available original document. 
in diameter, and containing a 15.25" diameter hole in each quadrant of the shield. The prepulse shield was situated in between the two water-filled cylinders.

Each switch pair was modeled as two metal spheres connected to supporting structures by metal rods. The two spheres are separated by a 2.756 " gap. A 2.75 "

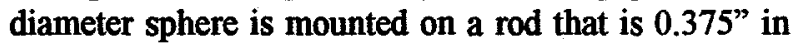
diameter, and 1.0" long on the input line. A 2.5" diameter sphere is mounted on a rod that is $\mathbf{0 . 7 5}$ " in diameter and 7.75" long on the output line. This side of the switch extends through the 15.25" diameter hole in the prepulse shield. The supporting structures were modeled as oblong shaped metal rings. The top ring was 6" wide and 9" long. The bottom ring was 2 " wide and 7" long. The four switches have a periodic symmetry about the center axis; consequently, only one quadrant of the model was needed to calculate the capacitance of the switches. The COULOMB 3-D model of the waterline with four switches is shown in Figure 1 where the waterline is rotated $90^{\circ}$ counterclockwise from the horizontal. One quadrant of the waterline section is presented in Figure 2.

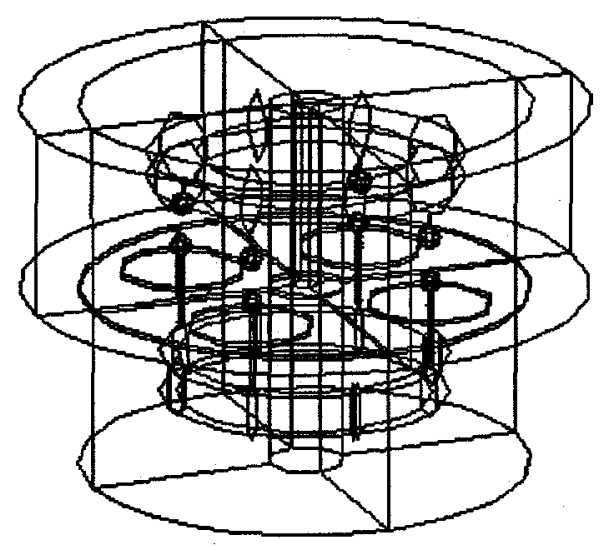

Figure 1. COULOMB 3-D model of the waterline switches on the $Z$-accelerator.

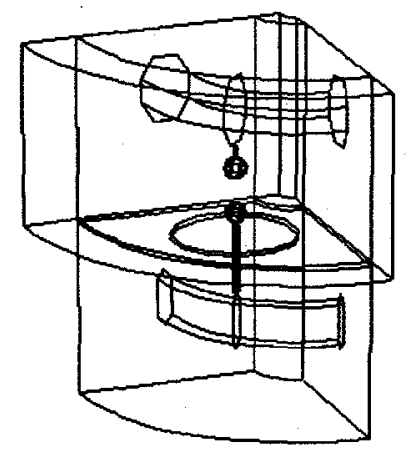

Figure 2. One quadrant of the waterline switch with prepulse shield.

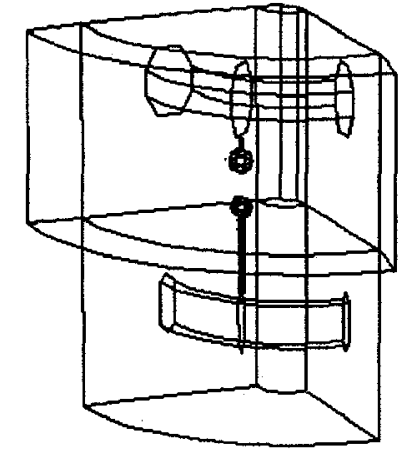

Figure 3. One quadrant of the waterline switch without a prepulse shield.

The upper volume, the lower volume, and the hole in the prepulse shield contained water as a dielectric $\left(\varepsilon_{\mathrm{r}}=81\right)$. The rear post in the upper volume was modeled as a polyethylene $\left(\varepsilon_{\mathrm{T}}=2.26\right)$ insulator. All other parts are metal and defined as four conductors. Conductor 1 is the upper electrode, rod, and support structure. Conductor 2 is the lower electrode, rod, and support structure. Conductor 3 is the outer wall of the top cylinder. Conductor 4 is the outer wall of the bottom cylinder, the prepulse shield, and the rear post of the bottom cylinder.

The model of the waterline switch without a prepulse shield is shown in Figure 3 where the waterline is rotated $90^{\circ}$ counterclockwise from the horizontal. The conductors were defined the same as the case with a prepulse shield except that Conductor 4 was made up of the outer wall of the bottom cylinder and the rear post.

\section{CAPACITANCE CALCULATIONS}

COULOMB uses the boundary element method to solve for field distributions and to calculate the inductance and capacitance of a system of conductors. COULOMB was used to calculate the capacitance of the switch electrodes and other conductors in the Zwaterlines. The conductors were assigned numbers as described above. The switch capacitance is given as $\mathrm{C}_{12}$, the capacitance from Conductor 1 to Conductor 2 , or as $\mathrm{C}_{21}$, the capacitance from Conductor 2 to Conductor 1. COULOMB calculated both for the switch configured with a prepulse shield and both for the switch without a prepulse shield.

The results of the switch capacitance calculations are presented in Table 1. 


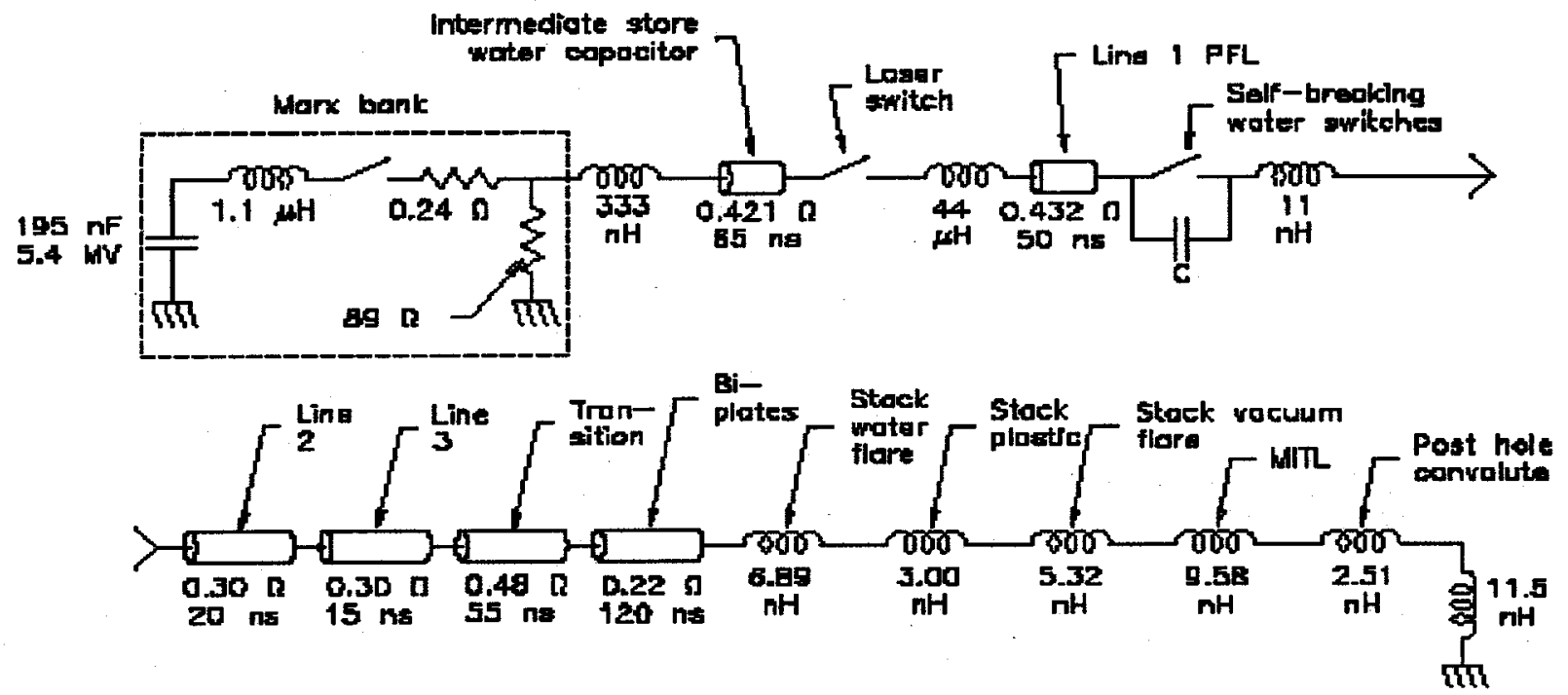

Figure 4. SCREAMER circuit model of one level of the Z-accelerator

Table 1. Capacitance of Z-waterline switch

\begin{tabular}{|l|c|c|}
\hline & 1 - switch & 4 - switches \\
\hline & & \\
\hline With PPS & $88 \mathrm{pF}$ & $352 \mathrm{pF}$ \\
\hline & & \\
\hline Without PPS & $255 \mathrm{pF}$ & $1020 \mathrm{pF}$ \\
\hline
\end{tabular}

\section{CIRCUIT MODEL OF Z}

The SCREAMER model of the $Z$-accelerator is presented in Figure 4. The circuit represents nine transmission lines in parallel on one of four levels. The capacitance, $\mathrm{C}$, across the switch represents the capacitance of four water line switches in parallel on each of the nine lines or 36 capacitors in parallel. The current output of the waterline is plotted in Figure 5 for the two cases of interest.

\section{ANALYSIS RESULTS}

The results of the COULOMB switch-capacitance calculations and the SCREAMER prepulse-current calculations are summarized in Table 2 for the $Z$ waterline switches configured with and without a prepulse shield.

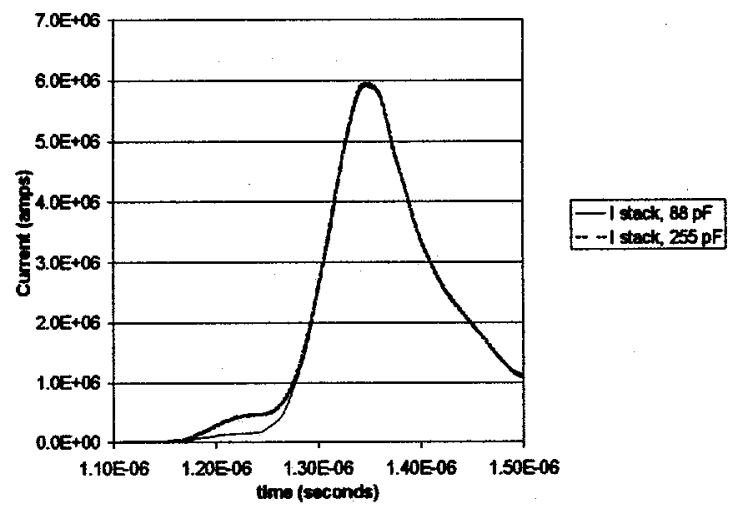

Figure 5. SCREAMER output current predictions for one level of the Z-accelerator.

Table 2. Capacitance and prepulse current summary.

\begin{tabular}{|l|l|l|}
\hline & $\begin{array}{l}\text { Switch } \\
\text { Capacitance }\end{array}$ & $\begin{array}{l}\text { I-prepulse } \\
@ 1.25 \mu \mathrm{sec}\end{array}$ \\
\hline & & \\
\hline With PPS & $88 \mathrm{pF}$ & $223 \mathrm{kA}$ \\
\hline & & \\
\hline Without PPS & $255 \mathrm{pF}$ & $473 \mathrm{kA}$ \\
\hline
\end{tabular}




\section{CONCLUSIONS}

It is apparent from the results that the prepulse shield does suppress the prepulse current. Use of the prepulse shield decreases the capacitance of the four waterline switches from $1020 \mathrm{pF}$ to $352 \mathrm{pF}$. On the other hand, if a greater prepulse current is desired, the prepulse shield could be removed.

The Z-accelerator contains several more switches in the waterline each equipped with prepulse shields. These switches are presently shorted out. The COULOMB and SCREAMER models developed in the subject study could be used to investigate the effects of varying the capacitance on multiple waterline switches on the electrical output of the Zaccelerator.

\section{REFERENCES}

[1] D. L. Johnson, J. P. VanDevender, and T. H. Martin, "Low Prepulse, High Power Density Water Dielectric Switching," in Proc. of IEEE Pulsed Power Conference, 1979, p. 191.

[2] A. Lorenz, F. N. Beg, J. Ruiz-Camacho, J. Worley, and A. E. Dangor, "Influence of a Prepulse Current on a Fiber Z Pinch," Physical Review Letters, Volume 81, Number 2, pp. 361-364, 13 July 1998.

[3] "COULOMB, Three-dimensional, Electric Field Solver, Version 4.0, Users and Technical Manual," Integrated Engineering Software, Winnipeg, Manitoba, Canada.

[4] M. L. Kiefer, K. L. Fugelso, K. W. Struve, M. M. Widner, "SCREAMER, A Pulsed Power Design Tool, User's Guide for Version 2.0," August 25, 1995. 